УДК 342

DOI 10.18413/2712-746X-2020-44-2-345-351

\title{
О конституционных обязанностях человека и гражданина
}

\author{
Цалиев А.М. \\ Северо-Кавказский горно-металлургический институт (ГТУ), \\ 362021, Россия, РСО-Алания, г. Владикавказ, ул. Николаева, 44 \\ E-mail: aronaron666@mail.ru
}

\begin{abstract}
Аннотация. На основе анализа теоретических подходов и формальных положений рассматрены исторические и современные грани конституционных обязанностей, признаваемых в качестве рациональной основы взаимодействия людей, организованных в общество и государство. Автор подчеркнул необходимость справедливого научного внимания к конституционным обязанностям и их адекватного представления в учебной юридической литературе. Дан сравнительный анализ каталогов конституционных обязанностей человека и гражданина в советских конституциях и Конституции России. Приведены примеры изменения конституционных акцентов в формулировании обязанностей человека и гражданина. Представлен анализ и критика конституционного положения о свободе труда.
\end{abstract}

Ключевые слова: Конституция Российской Федерации, конституционные права и свободы, каталог обязанностей, свобода труда.

Для цитирования: Цалиев А.М. 2020. О конституционных обязанностях человека и гражданина NOMOTHETIKA: Философия. Социология. Право. 45 (2): 345-351. DOI 10.18413/2712-746X-202044-2-345-351

\section{On the constitutional duties of a person and citizen}

\author{
Alexander M. Tsaliev \\ North Caucasian Mining and Metallurgical Institute (GTU) \\ 44 Nikolayev street, Vladikavkaz, RSO-Alania, Russia, 362021 \\ E-mail: aronaron666@mail.ru
}

\begin{abstract}
Based on the analysis of theoretical approaches and formal provisions, the article examines the historical and modern facets of constitutional duties, which are recognized as the rational basis for the interaction of people organized into society and the state. The author, in solidarity with the statement about the inseparability of rights and duties, emphasizes the need for fair scientific attention to the study of the constitutional duties of the individual and their adequate representation in the educational legal literature. A comparative analysis of the catalogues of constitutional duties of a person and a citizen provided for in the Soviet constitutions and the current Constitution of the Russian Federation is given. Examples of changes in constitutional accents in the formulation of duties addressed to a person and a citizen are given. The constitutional provision that labor is free is analyzed and criticized. Arguments are made in favor of interpreting labor as a constitutional duty.
\end{abstract}

Key words: The Constitution of the Russian Federation, constitutional rights and freedoms, catalog of duties, freedom of labor.

For citation: Tsaliev A.M. 2020. On the constitutional duties of a person and citizen. NOMOTHETIKA: Philosophy. Sociology. Law series. 45 (2): 345-351 (in Russian). DOI 10.18413/2712-746X-2020-44-2345-351 


\section{Введение}

Обязанности наряду с правами и свободами человека и гражданина являются базовыми элементами юридического статуса личности. Определенный набор обязанностей касается отношения как к другому человеку, так и к обществу и государству. Если говорить о конституционных обязанностях, то они имеют особое социальное значение, занимают доминирующее место во всей системе юридических обязанностей и оказывают определяющее воздействие на эту систему, конкретизируемую и развиваемую федеральным законодательством. Тем не менее, «одной из особенностей современного общества является отсутствие четкого осознания, что конституционные обязанности выступают в качестве необходимых и безусловных предпосылок свободы, устанавливаются в интересах как всего общества и государства, так и самой личности» [Хаматова, 2018, с. 56].

Отметим, что обязанности, действительно, есть «столь же необходимый элемент правового регулирования», сколь и права, и связывают как демократическое правовое социальное государство, так и личность. Они есть, как правильно утверждает Б.С. Эбзеев, «объективно необходимые и закономерные свойства всякой государственной организации общества, имманентные государственно организованному человеку, живущему в сообществе других людей и подчиненному определенному правопорядку, и сами являются неотъемлемым элементом этого правопорядка. Без обязанностей и ответственности личности, коррелирующих его свободе и правам, немыслима социальная солидарность как баланс интересов во взаимоотношениях самих граждан и их объединений, а также в их взаимоотношениях с государством» [Эбзеев, 2014, с. 14]. Неслучайно во всех советских конституциях в названии главы о правах предусматривались и обязанности.

В настоящее время, с учетом внешнеполитической и внутриполитической обстановки в стране, в значительной степени актуализируется работа по повышению социального статуса конституционных обязанностей, их соблюдению и выполнению. Ныне, как правильно отмечается в литературе, стало вполне очевидным, что «забвение существующих у каждой личности обязанностей перед другими людьми, перед социумом и государством не представляется верным» и что «пренебрежительное отношение к обязанностям неизбежно влечет нарушения в сфере прав и свобод личности» [Байниязов, 2001, с. 50].

Несмотря на сказанное, в научной литературе крайне малое внимание уделяется исследованию конституционных обязанностей человека и гражданина. Как следствие, данная тема практически не рассматривается в учебной литературе, даже специально посвященной конституционной материи. С такими выводами вряд ли кто не согласится из конституционалистов. Так, ознакомление с учебниками по конституционному праву позволяет сделать однозначный вывод, что в отличие от прав и свобод граждан их обязанностям уделено не более 1\% объема практически любого издания [Савин, 2012, с. 6]. Увы, но и Конституция России, по сравнению с советскими конституциями, уделила обязанностям граждан значительно меньше внимания. Во многом это объясняется тем, что текст российской Конституции верстался в условиях политической эйфории и абсолютного примата прав и свобод граждан перед государством, в противовес советской системе права, утверждавшей обратное. Рассмотрим доктринальные подходы к интерпретации конституционных обязанностей и содержания ряда из них.

\section{Обязанности личности: понятийный и генезисный ракурсы}

Обязанности представляют собой юридическую меру должного поведения. Обязанность наряду с правом - предпосылка свободы и в конечном счете выражает собственные интересы человека, даже если он этого не осознает [Апиян, 2001, с. 12]. Ввиду этого, полагаем, обязанностям уделялось изначальное и сопряженное с правами внимание. Подчеркивая значимость обязанностей в одноименном трактате, М.Т. Цицерон отметил, что 
каждой области жизни и деятельности отвечают свои обязанности, а их исполнение нравственный смысл жизни.

В последующей истории человечества практически никогда не отрицалось значение обязанностей человека. Рассуждения о6 обязанностях всегда имели место не только в литературе, но и получили закрепление в конституционных актах строя, пришедшего на смену феодализму [Эбзеев, 2014, с. 286]. Как ранее нами отмечалось, попытка принятия отдельного специального документа увенчалась успехом в конце XVIII века: Французский конвент в 1875 г. принял Декларацию обязанностей человека и гражданина. В ней впервые на государственном уровне были упомянуты обязанности человека. К ним были отнесены следующие: «не причинять другому того, чего вы не желали бы самим претерпеть от других; творить постоянно другим то благо, которое вы желали бы от них получить» [Цалиев, 2011, с. 27].

Положение о том, что «нет прав без обязанностей» получило международное признание. Так, об обязанностях говорится во Всеобщей декларации прав человека 1948 года: «Каждый человек имеет обязанности перед обществом, в котором только и возможно свободное и полное развитие его личности... Осуществление прав и свобод граждан требует должного признания и уважения прав и свобод других и удовлетворения справедливых требований морали, общественного порядка и общего благосостояния в демократическом обществе».

Включение положений об обязанностях человека и гражданина, «предусмотренных в упомянутых декларациях, нельзя рассматривать как нечто противоречащее демократическим принципам организации общества и государства. Напротив, они вытекают из факта общественного бытия и в единстве с правами образуют универсальный принцип демократической организации общественной жизни, о чем свидетельствует и конституционная практика ряда современных государств» [Цалиев, 2011, с. 27]. Тем не менее, видный ученый С.С. Алексеев и получивший к тому времени известность политик А.А. Собчак настойчиво предостерегали общество от закрепления в будущей Конституции Российской Федерации обязанностей человека и гражданина, убеждая его в том, что такое закрепление - якобы из числа советских традиций, «неведомых конституциям передовых стран» [Алексеев, Собчак, 1992].

Подробный анализ этого разрушительного тезиса ведет к отказу от рациональной основы взаимодействия людей, организованных в общество и государство. К счастью, ему дали достойный отпор, обратив при этом внимание на то, что после Второй мировой войны возобладали идеи не только о неотъемлемых, естественных правах и свободах человека и гражданина, но и об обязанностях. В силу понимания их социальной значимости обязанности нашли свое достойное место в конституционных текстах значительной части государств.

\section{Конституционные обязанности и вариации их видового ряда}

Вполне приемлемым полагаем следующее определение: «конституционные обязанности как равноценная составная часть правового статуса личности - это закрепленное конституционными нормами обязательное поведение человека и гражданина, когда на стороне государственных органов, органов местного самоуправления и физических лиц имеется право требовать выполнения предписанных конституцией правил» [Головистикова, Грудцына, 2006, с. 238].

Посредством установления четких юридических обязанностей индивида перед обществом и перед людьми наряду с провозглашением соответствующей системы субъективных прав и свобод достигается прочность и стабильность правового статуса граждан. «Без этого элемента правовое положение каждого отдельного человека было бы юридически необеспеченным и негарантированным» [Матузов, 1979, с. 86]. 
В Конституции России 1993 года формализован ряд обязанностей, адресованных человеку и гражданину. В их числе обязанности соблюдать Конституцию и федеральные законы (ч. 2 ст. 15); заботиться о детях, их воспитание - равное право и обязанность родителей (ч. 2 ст. 38); обязанность трудоспособных детей, достигших 18 лет, заботиться о нетрудоспособных родителях (ч. 3 ст. 38); получить основное общее образование (ч. 4 ст. 43); заботиться о сохранении исторического и культурного наследия, беречь памятники истории и культуры (ч. 3 ст. 44); платить законно установленные налоги и сборы (ст. 57); сохранять природу и окружающую среду, бережно относиться к природным богатствам (ст. 58); защищать Отечество и нести военную службу (ч.ч. 1, 2 ст. 59).

Сравнительный анализ указанных обязанностей с ранее действовавшими показывает, что произошли заметные изменения в их содержании и структуре. Так, перечень обязанностей в действующей Конституции Российской Федерации начинается с указания на «обязанность платить законно установленные налоги и сборы». В то же время в Конституции СССР перечень обязанностей начинался с указания на то, что «осуществление прав и свобод неотделимо от исполнения гражданами своих обязанностей». В соответствии со ст. 60 последней советской Конституции в числе первых - «обязанность и дело чести каждого способного к труду гражданина СССР - добросовестный труд в избранной им области общественно полезной деятельности, соблюдение трудовой дисциплины». Ни той, ни другой нормы в Конституции России нет. Более того, в ней, в отличие от советских и зарубежных конституций, во-первых, установлен запрет на принудительный труд, в то время как, например, Основной закон ФРГ допускает принудительный труд при лишении свободы; во-вторых, исключена норма об обязанности трудиться. Вместо этого предусмотрена ст. 37 Конституции России, в соответствии с которой «Труд свободен. Каждый имеет право свободно распоряжаться своими способностями к труду, выбирать род деятельности и профессию». Как видно, основной упор сделан на закрепление свободы труда.

Анализ данной конституционной нормы, если называть вещи своими именами, приводит к однозначному выводу о свободе человека на труд или тунеядство. Может быть слишком прямо сказано, но ведь многие специалисты так и толкуют ее, что совершенно правильно. Так, в одном из первых комментариев к Конституции Российской Федерации отмечено, что «свобода труда означает, прежде всего, свободный для гражданина выбор работать или не работать» [Конституция..., 1994, с. 210]. Такое разъяснение данной конституционной нормы дается также и в ряде других комментариев, в том числе в тех, которые носят доктринальный характер. Так, рассматривая свободу труда как конституционный принцип, авторы доктринального толкования к Конституции Российской Федерации полагают, что свобода труда «означает свободный для гражданина выбор - трудиться или не трудиться» [Конституция..., 2013, с. 185]. В учебной литературе студенту тоже объясняется, «что человек вправе как работать, так и не работать» [Баглай, 2013, с. 278].

Вот и возникают вопросы о возможностях социализации личности в таком свободном обществе; о труде как об одном из важнейших источников богатств общества, о перспективах такого общества.

Неужели указанные вопросы не задавали себе авторы, готовившие в начале 1990 гг. проект ныне действующей Конституции Российской Федерации? Однако в последующем, чтобы оправдать обоснованность нормы о свободе труда, некоторые авторы учебников и комментария к Конституции Российской Федерации стали утверждать, что она соответствует международным актам по данному вопросу. Так, в одном из них утверждается, что «Конституционная трактовка содержания прав в сфере труда полностью соответствует положениям Международного пакта об экономических, социальных и культурных правах» [Государственное..., 1996, с. 232]. Но это как раз и не соответствует действительности, поскольку в нем вовсе не упоминается свобода труда. С учетом изложенного целесообразно если не исключить из ч. 1 ст. 37 Конституции Российской Федерации, то заручиться ее официальным толкованием со стороны Конституционного Суда Российской Федерации. 
Можно еще привести примеры разного отношения к обязанностям в указанных конституциях. Например, если в советских конституциях защита Отечества рассматривалась как священный долг каждого советского гражданина, а воинская обязанность как почетная обязанность советских граждан, то в Конституции Российской Федерации в аналогичной статье опускается слово «священный». Приходится говорить и о неопределенности данной обязанности. Несомненно, обязанность защищать Отечество включает в себя и установленную этой же статьей обязанность по несению военной службы. Однако в полной мере обязанность по несению военной службы не входит в обязанность по защите Отечества, т. к. несение альтернативной службы (как замена военной службы по призыву) для российских граждан, чьим убеждениям или вероисповеданию противоречит несение военной службы, никакого отношения к защите Отечества не имеет.

В государственно-правовой идеологии среди конституционных обязанностей человека и гражданина большое значение имеет получение образования. Государство не уделяет ему должного внимания, поэтому в настоящее время оно утрачивает свою актуальность. Хотя образование, помимо получения соответствующей суммы знаний, играет существенную роль в формировании моральных устоев, норм, установок молодого поколения, его гражданской позиции, усвоении общекультурных и патриотических ценностей. Поэтому в советский период образованию уделяли большое внимание. Оно, согласно ст. 45 Конституции СССР, обеспечивалось бесплатностью всех видов образования, осуществлением всеобщего обязательного среднего образования молодежи, широким развитием профессионально-технического, среднего специального и высшего образования на основе связи обучения с жизнью, с производством; развитием заочного и вечернего образования; предоставлением государственных стипендий и льгот учащимся и студентам, бесплатной выдачей школьных учебников; возможностью обучения в школе на родном языке; созданием условий для самообразования.

К этому необходимо стремиться и ныне, когда Российская Федерация на конституционном уровне характеризуется как социальное государство. Для более глубокого понимания сущности и назначения конституционных обязанностей их следует классифицировать. Прежде всего следует различать обязанности человека и обязанности гражданина, которые во многом отличаются. Критерием разграничения обязанностей человека и гражданина в отечественной конституционной практике служит характер связи между личностью и государством - гражданство, безгражданство и иностранство. Обязанности человека имеют естественное происхождение, поскольку вытекают не из факта гражданства, а из естественного сочленства индивида в обществе, в котором только и возможно его становление как личности, и в этом смысле являются атрибутивными свойствами человеческой личности [Эбзеев, 2005, с. 285]. Обязанности человека неразрывно связаны с закономерностями развития общества и предопределяются уровнем социально-экономического, политического и культурного развития.

В отличие от обязанностей человека, обязанности гражданина вытекают из сочленства индивида в государстве, являются отражением государственно-правового качества личности. Они возлагаются на физических лиц, которые состоят только под личным верховенством государства и связаны с ним отношениями гражданства. На граждан, в отличие от иных лиц, пребывающих на территории государства, распространяется не только территориальное верховенство государства, но также его личное верховенство. Оно распространяется на граждан и тогда, когда они находятся за пределами территории своего государства, по общему правилу не освобождаются от обязанностей по отношению к нему. 
Вместе с тем нельзя абсолютизировать различия между обязанностями человека и гражданина, поскольку возможно изменение их правового статуса. Одно остается неизменным - их значение и ценность для общества и государства, самой личности.

\section{Заключение}

Проведенное исследование дает основания для следующих выводов. Обязанности, являясь признанным равноценным элементом правового статуса личности, тем не менее не получают достойного внимания в научной литературе. Сложившаяся ситуация зеркально воспроизведена и в учебной литературе, которая призвана, по замыслу, привить студентам рациональные основы взаимодействия людей, организованных в общество и государство.

Выявленное в историческом срезе смещение акцентов с абсолютизации обязанностей личности в сторону абсолютизации прав личности не представляется продуктивным в системе отношений человек (общество) - государство. Гармонизации данной сфере будет способствовать доктринальное обоснование, содержательное уточнение и конституционно-правовая формализация указанных элементов правового положения личности. Представляется, что верные акценты здесь по силам расставить Конституционному Суду Российской Федерации путем официального толкования.

В советский и российский периоды конституционного строительства закономерно изменялись не только конституционные каталоги обязанностей человека и гражданина, но и их градации, отражающие, как правило, характерные ценностные приоритеты того времени, когда принимались основные законы страны.

Дискуссия о свободе труда и об обязанности трудиться, по мнению автора, должна решаться в пользу долженствования, поскольку только так обеспечивается надлежащая социализация личности и понимание труда как одного из важнейших источников богатств общества.

\section{Список источников}

1. Алексеев С., Собчак А. 1992. Конституция и судьба России. Известия. 29 марта.

2. Баглай М.В. 2013. Конституционное право Российской Федерации: учеб. Для вузов. М., Изд-во Норма, 784 с.

3. Государственное право Российской Федерации: учебник. 1996. Под. ред. О.Е. Кутафина. М., 584 с.

4. Конституция Российской Федерации. Комментарий. 1994. Под общей ред. Б.Н. Топорнина, Ю.Н. Батурина, Р.Г. Орехова. М., Юрид. лит. 623 с.

5. Конституция Российской Федерации. Комментарий Российской Федерации. Доктринальный комментарий (постатейный). 2013. Рук. авт. кол. Ю.А. Дмитриев. Науч. ред. Ю.И. Скуратов. М., Статут, 688 с.

\section{Список литературы}

1. Апиян Н.А. 2001. Права человека: итоги века, тенденции, перспективы. Государство и право, 5: 89-98.

2. Байниязов Р.С. 2001. Мировоззренческие основы общероссийской правовой идеологии. Журнал российского права, 11: 46-52.

3. Головистикова А.Н., Грудцына Л.Ю. 2006. Права человека. М., 445 с.

4. Матузов Н.И. 1979. Юридические обязанности и ответственность как элементы правового статуса личности. В кн.: Конституция СССР и правовое положение личности. М., 81-88.

5. Савин И.Г. 2012. Правовое регулирование исполнения гражданами Российской Федерации конституционной обязанности по защите Отечества. Военно-юридический журнал, 2: 6-10.

6. Хаматова С.Х. 2018. Институт конституционных обязанностей человека и гражданина в системе правового федеративного государства. Государство и право, 9: 64-70. 
7. Цалиев А.М. 2011. Правовая культура и место в ней прав, свобод и обязанностей человека. Право и государство: теория и практика, 4 (76): 24-29.

8. Эбзеев Б.С. 2005. Человек, народ, государство в конституционном строе Российской Федерации. М., 576 с.

9. Эбзеев Б.С. 2014. Конституция, власть и свобода в России. Опыт синтетического исследования. М., 336 с.

\section{References}

1. Apiyan N.A. 2001. Prava cheloveka: itogi veka, tendencii, perspektivy. [Human rights: results of the century, trends, prospects]. Gosudarstvo i pravo, 5: 89-98. (in Russian)

2. Bayniyazov R.S. 2001 Mirovozzrencheskie osnovy obshcherossijskoj pravovoj ideologii. [The Ideological foundations of the Russian legal ideology]. ZHurnal rossijskogo prava, 11: 46-52.

3. Ebzeev B.S. 2005. CHelovek, narod, gosudarstvo v konstitucionnom stroe Rossijskoj Federacii [Man, people, state in the constitutional order of the Russian Federation]. M., $576 \mathrm{p}$.

4. Ebzeev B.S. 2014. Konstituciya, vlast' i svoboda v Rossii. Opyt sinteticheskogo issledovaniya [Constitution, power and freedom in Russia. Experience of synthetic research] M., 336 p. (in Russian)

5. Golovistikova A.N., Grudtsina L.Yu. 2006. Prava cheloveka [Human rights] Moscow, 445 p.

6. Khamatova S.H. 2018. Institut konstitucionnyh obyazannostej cheloveka i grazhdanina v sisteme pravovogo federativnogo gosudarstva [Institute of constitutional duties of a person and a citizen in the system of a legal Federal state]. Gosudarstvo i pravo, 9: 64-70.

7. Matuzov N.I. 1979. YUridicheskie obyazannosti i otvetstvennost' kak elementy pravovogo statusa lichnosti. [Legal duties and responsibilities as elements of a person's legal status]. In: Konstituciya SSSR i pravovoe polozhenie lichnosti. [Constitution of the USSR and the legal status of the individual]. M., 81-88.

8. Savin I.G. 2012. Pravovoe regulirovanie ispolneniya grazhdanami Rossijskoj Federacii konstitucionnoj obyazannosti po zashchite Otechestva. [Legal regulation of the execution by citizens of the Russian Federation of the constitutional duty to protect the Fatherland]. Voenno-yuridicheskij zhurnal, 2: 6-10.

9. Tsaliev A.M. 2011. Pravovaya kul'tura i mesto v nej prav, svobod i obyazannostej cheloveka. [Legal culture and the place in it of the rights, freedoms and duties of man]. Pravo i gosudarstvo: teoriya i praktika, 4 (76): 24-29.

\section{ИНФОРМАЦИЯ ОБ АВТОРЕ}

Цалиев Александр Михайлович, доктор юридических наук, профессор, заведующий кафедрой конституционного и административного права юридического факультета $\mathrm{Ce}$ веро-Кавказского горно-металлургического института (ГТУ), г. Владикавказ, Россия

\section{INFORMATION ABOUT THE AUTHOR}

Alexander M. Tsaliev, doctor of law, Professor, head of the Department of constitutional and administrative law, faculty of law of the North Caucasus mining and metallurgical Institute (GTU), Vladikavkaz, Russia 